\title{
Papers
}

\section{Montelukast and fluticasone compared with salmeterol and fluticasone in protecting against asthma exacerbation in adults: one year, double blind, randomised, comparative trial}

Leif Bjermer, Hans Bisgaard, Jean Bousquet, Leonardo M Fabbri, Andrew P Greening, Tari Haahtela, Stephen T Holgate, Cesar Picado, Joris Menten, S Balachandra Dass, Jonathan A Leff, Peter G Polos

\begin{abstract}
Objectives To assess the effect of montelukast versus salmeterol added to inhaled fluticasone propionate on asthma exacerbation in patients whose symptoms are inadequately controlled with fluticasone alone. Design and setting A 52 week, two period, double blind, multicentre trial during which patients whose symptoms remained uncontrolled by inhaled corticosteroids were randomised to add montelukast or salmeterol.

Participants Patients (15-72 years; $n=1490$ ) had a clinical history of chronic asthma for $\geq 1$ year, a baseline forced expiratory volume in one second $\left(\mathrm{FEV}_{1}\right)$ value $50-90 \%$ predicted, and a $\beta$ agonist improvement of $\geq 12 \%$ in $\mathrm{FEV}_{1}$.

Main outcome measures The primary end point was the percentage of patients with at least one asthma exacerbation.

Results 20.1\% of the patients in the group receiving montelukast and fluticasone had an asthma exacerbation compared with $19.1 \%$ in the group receiving salmeterol and fluticasone; the difference was $1 \%$ (95\% confidence interval $-3.1 \%$ to $5.0 \%)$. With a risk ratio (montelukast-fluticasone/ salmeterol-fluticasone) of 1.05 (0.86 to 1.29), treatment with montelukast and fluticasone was shown to be non-inferior to treatment with salmeterol and fluticasone. Salmeterol and fluticasone significantly increased $\mathrm{FEV}_{1}$ before a $\beta$ agonist was used and morning peak expiratory flow compared with montelukast and fluticasone $(\mathrm{P} \leq 0.001)$, whereas $\mathrm{FEV}_{1}$ after a $\beta$ agonist was used and improvements in asthma specific quality of life and nocturnal awakenings were similar between the groups. Montelukast and fluticasone significantly $(\mathrm{P}=0.011)$ reduced peripheral blood eosinophil counts compared with salmeterol and fluticasone. Both treatments were generally well tolerated.

Conclusion The addition of montelukast in patients whose symptoms remain uncontrolled by inhaled fluticasone could provide equivalent clinical control to salmeterol.
\end{abstract}

\section{Introduction}

Anti-inflammatory treatment with inhaled corticosteroids improves lung function, decreases symptoms, reduces asthma exacerbations, and has been the cornerstone of treatment for more than two decades. ${ }^{1}$ Current guidelines recommend inhaled corticosteroids as first line treatments for patients with persistent asthma. ${ }^{12}$ However, many patients remain symptomatic despite inhaled corticosteroid treatment, and inflammation of the airways may persist during treatment with inhaled and even oral corticosteroids. ${ }^{3}$ Increasing the dose of inhaled corticosteroids is one therapeutic option. However, at higher doses side effects become a concern due to a narrow therapeutic index, and responses are variable, ${ }^{4}$ implying that such doses may not necessarily treat asthma more effectively. Adding an inhaled long acting $\beta$ agonist to an inhaled corticosteroid is more effective in improving lung function and reducing symptoms ${ }^{56}$ and asthma exacerbations. ${ }^{7}$ Combination treatment is therefore recommended in current guidelines to achieve additional control. ${ }^{2}$ An alternative approach is to add a leukotriene receptor antagonist to an inhaled corticosteroid. ${ }^{8}$ Cysteinyl leukotrienes released by eosinophils and mast cells mediate pro-inflammatory events in asthma. ${ }^{9}$ Montelukast is a leukotriene receptor antagonist that improves asthmatic inflammation and prevents bronchoconstriction. ${ }^{10-12}$

The addition of a long acting $\beta$ agonist or a leukotriene receptor antagonist to inhaled corticosteroids has been shown to prevent exacerbations and improve quality of life, ${ }^{13}{ }^{14}$ but few data are available to compare the benefits of these alternative strategies. We report a randomised controlled trial of adding salmeterol or montelukast to an inhaled corticosteroid for patients who remained symptomatic while using an inhaled corticosteroid alone, which assessed the rate of asthma exacerbations over a one year period.

\section{Methods}

Study design and patients

This study was a randomised, double blind, double dummy, parallel group, multicentre study of 52 weeks
Department of Respiratory Medicine and Allergology, University Hospital, SE-221 85 Lund, Sweden Leif Bjermer professor

Department of Paediatrics, Copenhagen University Hospital, Gentofte, Niels Andersens Vej 65 DK-2900 Copenhagen,

Denmark Hans Bisgaard professor

Service des Maladies Respiratoires, Hospital Arnaud de Villeneuve, F-34295 Montpellier, Cedex 5 , France Jean Bousquet professor

Department of Respiratory Diseases, University of Modena, Largo del Pozzo 71, I-41100 Modena, Italy

Leonardo M Fabbri professor

continued over

bmj.com 2003;327:891

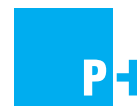

The full list of investigators appears on bmj.com 
Respiratory Medicine Unit, Western General Hospital, Edinburgh EH4 2XU

Andrew P Greening professor

Department of Allergology, Helsinki University Hospital,

FIN-00029HUS

Helsinki, Finland Tari Haahtela professor

Respiratory, Cell and Molecular Biology Research Division,

Southampton General Hospital Southampton SO16 6YD Stephen T Holgate professor

Servei de

Pneumolgia, Institut de Pneumologia, Hospital Clinic University of Barcelona, E-08036 Barcelona, Spain

Cesar Picado professor

Merck and Company Incorporated, WS3D-50 One Merck Drive, Whitehouse Station, NJ 08889, USA Joris Menten biometrician

S Balachandra Dass clinical associate Jonathan A Leff senior director Peter G Polos director

Correspondence to: Peter G. Polos peter_polos@ merck.com including a four week run-in period when patients received non-blinded inhaled dry powder fluticasone $100 \mu \mathrm{g}$ twice daily. During the last two weeks of this period, single blind placebo salmeterol (metered dose inhaler) and placebo montelukast were added. A 48 week period of double blind, double dummy treatment followed, during which in addition to fluticasone $100 \mu \mathrm{g}$ twice daily, patients received either montelukast $10 \mathrm{mg}$ once daily (in the evening) or salmeterol $50 \mu \mathrm{g}$ twice daily. Allocation numbers were sequentially assigned at each study site and were associated with treatment groups by use of a computer generated allocation schedule. Block randomisation was used at each site. The blinded, double dummy, clinical supplies were labelled with allocation numbers and patient instructions. The study was conducted between January 2000 and December 2001. Patients gave written informed consent.

Patients were aged 15-72 years and had a history of chronic asthma for one year or longer, a baseline forced expiratory volume in one second $\left(\mathrm{FEV}_{1}\right)$ of $50-90 \%$ predicted, and an improvement of $12 \%$ or more in $\mathrm{FEV}_{1}$ or in morning peak expiratory flow (PEF) after using a $\beta$ agonist. Other inclusion criteria included regular use of an inhaled corticosteroid (equivalent to beclomethasone $200-1000 \mathrm{mg}$ per day) for at least eight weeks before the run-in period, an average use of $\beta$ agonist of one puff or more per day, and a pre-specified minimum biweekly daytime symptom score. We excluded patients who received oral corticosteroids in the preceding month; chromones, leukotriene receptor antagonists, long acting inhaled or oral $\beta$ agonists, or inhaled anticholinergics during the preceding two weeks; and patients who received theophylline or antihistamines during the week preceding the first visit. A placebo arm was not included because the study was designed as a comparison with standard care in symptomatic patients and because of ethical concerns that it would be inappropriate not to provide active treatment to patients whose symptoms remained uncontrolled by fluticasone during the one year duration of the study.

The primary end point was the percentage of patients with at least one asthma exacerbation, defined as worsening asthma requiring an unscheduled visit to a doctor, emergency department, or hospital or treatment with oral, intravenous, or intramuscular corticosteroids. Secondary end points included asthma specific quality of life, ${ }^{15}$ nocturnal awakenings, use of resources, mean $\mathrm{FEV}_{1}$ values before and after using a $\beta$ agonist, and mean percentage increase in $\mathrm{FEV}_{1}$ after using a $\beta$ agonist, mean morning peak expiratory flow, time to first asthma exacerbation, and peripheral blood eosinophil counts. Four Finnish centres assessed airway inflammation by marker assays in induced sputum in a subgroup of 41 patients (25 patients in the montelukast and 16 patients in the salmeterol group), as described earlier. ${ }^{16}$

\section{Statistical analysis}

We included all patients who received at least one day of double blind treatment in the modified analysis by intention to treat of asthma exacerbations (primary end point). We performed a modified analysis by intention to treat on all patients with prerandomisation baseline values and at least one measurement during the treatment period. We chose the sample size to provide $80 \%$ power to show that the risk of experiencing at least one asthma exacerbation with montelukast added to fluticasone was less than 1.33 times the same risk with salmeterol added to fluticasone. This sample size calculation used data from previous work ${ }^{78}$ and was based on an assumed percentage of patients with asthma exacerbations equal to $23 \%$ on the combination of montelukast and fluticasone and equal to $24 \%$ on the combination of salmeterol and fluticasone. We used a generalised linear model with binomial distribution and logarithmic link function to calculate the ratio of the percentages of patients with asthma exacerbations in the two groups and 95\% confidence intervals. We considered the combination of montelukast and fluticasone non-inferior to the combination of salmeterol and fluticasone if the upper limit of the two sided 95\% confidence interval for the risk ratio was below 1.33 . We chose 1.33 as our inferiority limit to preserve at least half of the active treatment effect and to represent a difference of 0.29 in the $\log$ scale. This corresponds to $44 \%$ of the effect of montelukast added to beclomethasone, which was 0.66 on the log scale. ${ }^{8}$ This conforms to guidelines from the international conference on harmonisation, ${ }^{17}$ which require the non-inferiority limit to be smaller than the difference observed versus placebo in superiority trials. We used the Kaplan-Meier method to estimate for each treatment group the cumulative percentage of patients with asthma exacerbations. We used Poisson regression with robust variance estimates for a secondary analysis of the number of asthma exacerbations.

We used an analysis of covariance model with effects for treatment and centre, and we used the baseline value as a covariate analysed differences in treatment for blood eosinophil count, asthma specific quality of life, nocturnal awakening, peak expiratory flow, and $\mathrm{FEV}_{1}$ as a change from baseline. We used generalised linear models, similar to models used for analysing the percentage of patients with asthma exacerbations, to analyse differences between treatments for use of resources. We used Kaplan-Meier curves along with the corresponding Wilcoxon statistic to conduct analyses of the time to event for first asthma exacerbations and use of resources.

We included all randomised patients in the safety analyses. We assessed safety by statistical and clinical review of adverse experiences.

\section{Results}

Patient disposition and baseline characteristics We screened 2144 patients from 148 sites and 37 countries, and 1490 were entered into the study. Of these, 747 participants were randomised to the montelukast-fluticasone group and 743 to the salmeterol-fluticasone group (table 1). Discontinuance of patients was similar between both treatment groups. We found no differences between the two groups for baseline characteristics (table 2), including history of nocturnal asthma or previous use of inhaled corticosteroids (dosage and type; data not shown).

\section{Efficacy end points}

Of the patients in the montelukast-fluticasone group $20.1 \%(150 / 747)$ had at least one asthma exacerbation, 
compared with $19.1 \%(142 / 743)$ for the salmeterolfluticasone group (table 3). The difference was 1\% (95\% confidence interval $-3.1 . \%$ to $5.0 \%)$. The risk ratio (montelukast-fluticasone/salmeterol-fluticasone) was 1.05 (0.86 to 1.29 ). As the upper limit of the $95 \%$ confidence interval for the risk ratio was less than 1.33 we considered treatment with montelukast and fluticasone to be non-inferior to treatment with salmeterol and fluticasone. Results from a per protocol analysis confirmed the above result by intention to treat: the estimated risk ratio in the per protocol population was 1.02 (0.82 to 1.26). Analysis-by using the KaplanMeier method, which accounts for censored observations (such as dropouts) - of the estimated cumulative percentage of patients with an asthma exacerbation during the treatment period supported the primary analysis: montelukast and fluticasone $21.8 \%$ and salmeterol and fluticasone $20.6 \%$, with the estimated risk ratio of 1.06 in favour of salmeterol and fluticasone (0.86 and 1.30). We found no difference between the two treatment groups in the time to the first asthma exacerbation (fig 1).

An analysis of the distribution of patients according to the number of asthma exacerbations ( 1 to 6 ) showed no difference between the two groups. Of the patients in the montelukast-fluticasone group $(n=747)$, the proportion (number) with zero, one, two, three, or four to six asthma exacerbations was $79.9 \%$ (597), $13.7 \%$ (102), 3.5\% (26), 2.0\% (15), and 0.9\% (7), respectively. Among the patients in the salmeterol-fluticasone group $(\mathrm{n}=743)$, the comparable proportions (numbers) were $80.9 \%$ (601), $14.3 \%$ (106), $3.0 \%$ (22), $0.9 \%$ (7), and $0.9 \%(7)$. Patients receiving montelukast and fluticasone averaged 0.37 exacerbations per year compared with 0.32 for patients receiving salmeterol and fluticasone. The characteristics of the exacerbations in both groups were identical (table 3).

Both treatments significantly decreased nocturnal awakenings (number of nights per week) compared with baseline $(\mathrm{P} \leq 0.001)$. The two groups showed no significant difference for nocturnal awakenings averaged over the 48 week treatment period (least squares mean (standard error) change from baseline was - 1.68 (0.06) nights per week (montelukast-fluticasone) versus -1.74 (0.06) (salmeterol-fluticasone)). The asthma specific quality of life score significantly improved from baseline for both treatments $(\mathrm{P} \leq 0.001)$ : the least squares mean (SE) change from baseline was $0.71 \quad(0.04)$ (montelukast-fluticasone group) versus $0.76 \quad(0.04)$ (salmeterol-fluticasone group), with no significant difference between the two groups.
Table 1 Participants in the randomised, double blind, double dummy, parallel group, multicentre study of 52 weeks including a four week run-in period. Values are numbers (percentages) of patients

\begin{tabular}{lcc} 
& Montelukast-fluticasone $(\mathbf{n}=\mathbf{7 4 7})$ & Salmeterol-fluticasone $(\mathbf{n}=\mathbf{7 4 3})$ \\
\hline Completed the study & $622(83.3)$ & $633(85.2)$ \\
\hline Discontinued the study & $125(16.7)$ & $110(14.8)$ \\
\hline Clinical adverse experience & $38(5.1)$ & $35^{\star}(4.7)$ \\
\hline Laboratory adverse experience & $0(0)$ & $2(0.3)$ \\
\hline Lack of efficacy & $4(0.5)$ & $7(0.9)$ \\
\hline Protocol deviation & $15(2.0)$ & $15(2.0)$ \\
\hline Lost to follow up & $12(1.6)$ & $12(1.6)$ \\
\hline Patient moved & $7(0.9)$ & $5(0.7)$ \\
\hline Withdrew consent & $22(2.9)$ & $22(3.0)$ \\
\hline Site terminated & $8(1.1)$ & $4(0.5)$ \\
\hline Other reasons & $19(2.5)$ & $8(1.1)$ \\
\hline
\end{tabular}

2144 patients were screened, and 1490 patients were entered into the study.

${ }^{*}$ One patient discontinued because of an adverse experience of vomiting that started before randomisation.

Table 2 Patients' demographics and baseline characteristics. Data are means (SD) unless otherwise indicated

\begin{tabular}{|c|c|c|}
\hline & $\begin{array}{l}\text { Montelukast-fluticasone group } \\
(\mathrm{n}=747)\end{array}$ & $\begin{array}{l}\text { Salmeterol-fluticasone group } \\
(n=743)\end{array}$ \\
\hline No (\%) of female participants & $408(54.6)$ & $410(55.2)$ \\
\hline Age (years) & $41.2(13.6)$ & $41.0(13.7)$ \\
\hline Age range (years) & $15-68$ & $15-72$ \\
\hline \multicolumn{3}{|l|}{$\begin{array}{l}\text { No (\%) of participants of ethnic } \\
\text { groups }\end{array}$} \\
\hline White & $581(77.8)$ & $575(77.4)$ \\
\hline Black & $7(0.9)$ & $4(0.5)$ \\
\hline Asian & $51(6.8)$ & $55(7.4)$ \\
\hline Other & $108(14.5)$ & $109(14.7)$ \\
\hline $\begin{array}{l}\text { Daily symptom score (max of } \\
24.0)\end{array}$ & $9.0(3.4)$ & $8.9(3.6)$ \\
\hline Use of $\beta$ agonist (puffs/day) & $3.3(2.5)$ & $3.3(2.2)$ \\
\hline $\begin{array}{l}\text { Overall quality of life score (max } \\
\text { of } 7.0 \text { ) }\end{array}$ & $4.7(1.0)$ & $4.7(1.0)$ \\
\hline $\mathrm{FEV}_{1}$ before $\beta$ agonist (I) & $2.4(0.8)$ & $2.5(0.8)$ \\
\hline $\mathrm{FEV}_{1} \%$ predicted & $71.3(13.2)$ & $72.7(13.9)$ \\
\hline $\begin{array}{l}\mathrm{FEV}_{1} \% \text { reversibility after a } \beta \\
\text { agonist was used }\end{array}$ & $18.4(12.3)$ & $18.8(13.0)$ \\
\hline $\begin{array}{l}\text { Peak expiratory flow in the } \\
\text { morning }(1 / \mathrm{min})\end{array}$ & $384(103)$ & $389(106)$ \\
\hline $\begin{array}{l}\text { No of nocturnal awakenings } \\
\text { (days/week) }\end{array}$ & $2.6(2.4)$ & $2.5(2.4)$ \\
\hline
\end{tabular}

Patients in both treatment groups showed significant increases $(\mathrm{P} \leq 0.001)$ from baseline in $\mathrm{FEV}_{1}$ before using a $\beta$ agonist throughout the 48 week treatment period (least squares mean (SE) change from baseline of 0.11 (0.02) (montelukast-fluticasone) versus 0.19 (0.02) (salmeterol-fluticasone), $\mathrm{P} \leq 0.001$ for difference between groups). We found no significant difference between the treatment groups with respect to the change from baseline in $\mathrm{FEV}_{1}$ after using a $\beta$ agonist

Table 3 Numbers (percentages) with 95\% confidence intervals of all patients in the treatment group with at least one asthma exacerbation and components during the 48 week period of double blind treatment

\begin{tabular}{|c|c|c|c|}
\hline & $\begin{array}{l}\text { Montelukast-fluticasone group } \\
\qquad(\mathrm{n}=747)^{*}\end{array}$ & $\begin{array}{l}\text { Salmeterol-fluticasone group } \\
(\mathrm{n}=743)^{\star}\end{array}$ & $\begin{array}{c}\text { Comparison between treatment } \\
\text { groups: risk ratio } \dagger\end{array}$ \\
\hline Asthma exacerbation $\ddagger$ & $150(20.1 ; 17.3$ to 23.1$)$ & $142(19.1 ; 16.3$ to 22.1$)$ & 1.05 (0.86 to 1.29$)$ \\
\hline Admission to hospital & $5(0.7 ; 0.2$ to 1.6$)$ & $7(0.9 ; 0.4$ to 1.9$)$ & 0.71 (0.21 to 2.22$)$ \\
\hline $\begin{array}{l}\text { Unscheduled visit to medical } \\
\text { specialist }\end{array}$ & $82(11.0 ; 8.8$ to 13.4$)$ & $80(10.8 ; 8.6$ to 13.2$)$ & $1.02(0.76$ to 1.36$)$ \\
\hline Visit to emergency department & $21(2.8 ; 1.7$ to 4.3$)$ & $21(2.8 ; 1.8$ to 4.3$)$ & $0.99(0.55$ to 1.81$)$ \\
\hline $\begin{array}{l}\text { Use of oral, intramuscular, } \\
\text { intravenous, or rectal corticosteroid }\end{array}$ & $118(15.8 ; 13.3$ to 18.6$)$ & $107(14.4 ; 12.0$ to 17.1$)$ & $1.10(0.86$ to 1.40$)$ \\
\hline
\end{tabular}

${ }^{*}$ Confidence interval (exact).

tConfidence interval (generalised linear regression model including treatment as factor).

¥Patients can have more than one asthma exacerbation but are counted once in a category. 


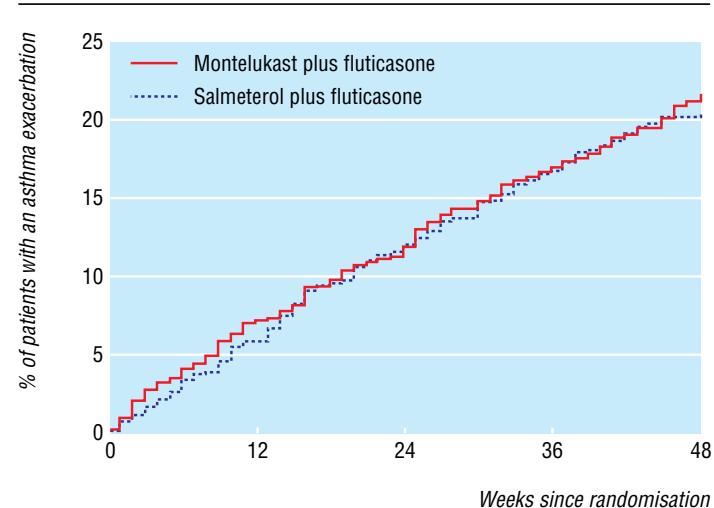

Fig 1 Cumulative percentage of patients with asthma exacerbations $(\mathrm{P}=0.599$ by log rank test)

when averaged over the treatment period (difference in least squares means $0.02,95 \%$ confidence interval -0.02 to 0.06 ). The montelukast-fluticasone group showed a significantly smaller decrease from baseline in percentage reversibility in $\mathrm{FEV}_{1}$ compared with the salmeterol-fluticasone group (least squares mean (SE) change from baseline of $-7.54(0.40)$ versus -11.26 (0.40), $\mathrm{P} \leq 0.001$ for difference between groups).

Patients receiving salmeterol and fluticasone had a significantly larger increase in morning peak expiratory flow (litres per minute) compared with patients receiving montelukast and fluticasone (least squares mean (SE) change from baseline of 34.59 (1.70) versus 17.73 (1.69), $\mathrm{P} \leq 0.001)$. Both treatments significantly improved peak expiratory flow over baseline values $(\mathrm{P} \leq 0.001)$. Montelukast added to fluticasone significantly reduced peripheral blood eosinophil counts $\left(10^{3} / \mu \mathrm{l}\right)$ compared with baseline (least squares mean (SE) change -0.04 (0.01), $\mathrm{P} \leq 0.001$; fig 2), whereas salmeterol added to fluticasone did not $(-0.01(0.01)$, $\mathrm{P}>0.05)$. In the induced sputum subgroup study, the numbers of eosinophils in sputum decreased significantly over the 48 week period in the montelukastfluticasone group (mean eosinophil score from 1.52 to 0.91 (on a scale of $0-3$ ), $\mathrm{P}<0.005$ ), whereas they did not change significantly in the salmeterol-fluticasone group (mean eosinophil score from 1.50 to 1.79).

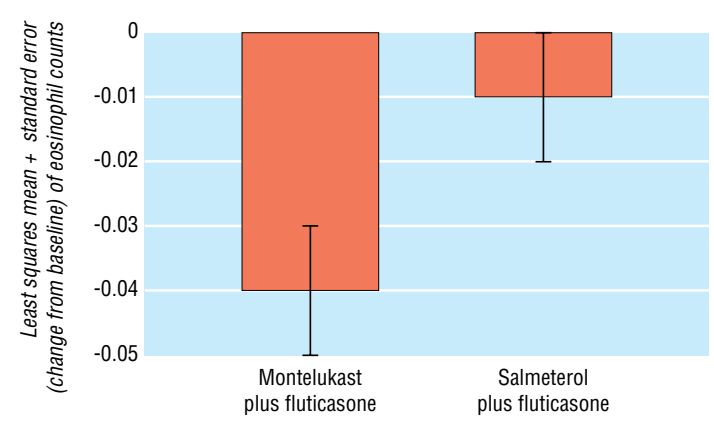

Fig 2 Change from baseline in peripheral blood eosinophil counts $\left(10^{3} / \mu \mathrm{l}\right)$ averaged over the 48 week treatment period ( $P=0.011$ for difference between groups). Mean baseline (during prerandomisation, run-in period) levels of eosinophil counts were $0.34 \times 10^{3} / \mu \mathrm{l}$ in the montelukast-fluticasone group and $0.31 \times 10^{3} / \mu$ in the salmeterol-fluticasone group

\section{Safety}

Clinical adverse experiences were reported by 530 $(71.0 \%)$ and $538(72.4 \%)$ patients in the montelukastfluticasone and salmeterol-fluticasone groups, respectively. Patients receiving salmeterol and fluticasone had a significantly higher incidence of drug related adverse experiences compared with patients receiving montelukast and fluticasone $(10.0 \%$ v $6.3 \%, \mathrm{P}=0.01)$. Patients receiving salmeterol and fluticasone also had a significantly higher incidence of serious adverse experiences $(7.4 \% v 4.6 \%, \mathrm{P}=0.022)$. One patient in the salmeterolfluticasone group died 15 days after the start of treatment with a severe asthma attack that was reported by the investigator as possibly related to study treatment. Laboratory adverse experiences were reported by $83(11.4 \%)$ and $85(11.7 \%)$ patients in the montelukast-fluticasone and salmeterol-fluticasone groups, respectively. One patient reported serious laboratory adverse experiences (neutropenia; and increased lymphocytes, alanine aminotransferase, aspartate aminotransferase, and alkaline phosphatase) in the salmeterol-fluticasone group, and none in the montelukast-fluticasone group.

\section{Discussion}

Adding montelukast to the treatment of patients who continue to experience symptoms while receiving inhaled fluticasone is at least as effective as adding salmeterol to treatment in these patients. Furthermore, the difference in the proportion of patients with asthma exacerbations between the two treatment groups in our study was small, (1\%, 95\% confidence interval -3.1 to 5.0 ), indicative of a difference that is not clinically important

Asthma exacerbations increase morbidity and mortality in patients, decrease their quality of life, and increase the cost of treatment. The percentage of patients with asthma exacerbations was therefore chosen as the primary end point of this study. Asthma exacerbations occurred in only $19-20 \%$ of patients over one year, indicating good overall control in both treatment groups. By comparison, in another similarly designed study currently under analysis, the proportion of patients with an asthma exacerbation was found to be lower in patients treated with salmeterol. Our results compare favourably with those of a previously reported one year study, where high dose budesonide and formoterol provided protection against severe asthma exacerbations (defined as requiring treatment with oral glucocorticoids or causing a decrease in morning peak expiratory flow of more than $30 \%$ below the baseline value on two consecutive days) in about $81 \%$ of patients, with an estimated yearly asthma exacerbation rate of 0.34 per patient.

\section{Added montelukast provides equivalent control to} added salmeterol

Given the importance of chronic inflammation in the pathogenesis of asthma, ${ }^{18}$ international guidelines have assigned increasing importance to the use of anti-inflammatory agents such as inhaled corticosteroids. ${ }^{1}$ Nevertheless, the addition of a second agent has been shown convincingly to reduce asthma exacerbations more than with inhaled corticosteroids 
alone. ${ }^{719}$ Thus international guidelines now advocate treatment with long acting $\beta$ agonists added to inhaled corticosteroids. Treatment with leukotriene modifiers represents an alternative combination strategy. The production of cysteinyl leukotrienes has been shown to be unaffected by steroids, ${ }^{20}{ }^{21}$ and treatment with leukotriene receptor antagonists is known to suppress inflammation in asthma as well as prevent bronchoconstriction. The addition of a leukotriene receptor antagonist to an inhaled corticosteroid therefore represents a reasonable and alternative therapeutic option for the treatment of asthma patients whose symptoms remain uncontrolled on inhaled corticosteroids. The $95 \%$ confidence limit of 1.33 of the risk ratio was chosen before the study and was based on guidelines from the international conference on harmonisation. ${ }^{17}$ The components of the primary end point (unscheduled visit to doctor or emergency department, admission to hospital, use of oral corticosteroids) were similar in both treatment groups. Both groups seemed to achieve good overall control: only $16 \%$ of patients in the montelukast-fluticasone group and $14 \%$ in the salmeterol-fluticasone group required oral corticosteroids compared with $32 \%$ in each group that had used oral corticosteroids for worsening asthma in the year preceding the study (data not shown). Also $12.6 \%$ of patients in the montelukastfluticasone group and $12.2 \%$ of patients in the salmeterol-fluticasone group had visits to health services, hospital, or emergency departments as opposed to $62 \%$ of patients in each group who made visits for worsening asthma during the previous year.

\section{Comparison with other studies}

Two short term (12 week) studies have compared asthma exacerbation rates in patients treated with either montelukast or salmeterol added to inhaled corticosteroids. Fish et al showed that the number of patients experiencing at least one exacerbation was similar in both groups $(6 \%$ in the salmeterol group $v$ $5 \%$ in the montelukast group). ${ }^{22}$ In the study by Nelson et al exacerbation rates were lower in the salmeterol group ( $2 \% v 6 \%)$, but the patients included showed an excellent responsiveness to $\beta$ agonists (23-24\%); the end point definition included elements of $\beta$ agonist responsiveness, and patients were followed for only 12 weeks. ${ }^{23}$ In our study, although salmeterol and fluticasone seem to be initially more effective, confluence of the two lines representing the cumulative percentage of patients with asthma exacerbations is at approximately 15 weeks. This finding may account for the differences between the short term results reported by others and the longer term results reported in this paper.

\section{Other efficacy end points}

Both drugs significantly decreased the frequency of nocturnal awakening, a variable exacerbation of the underlying asthma condition that is associated with an increased influx of inflammatory cells, particularly lymphocytes, macrophages, and eosinophils, into the small and peripheral airways. ${ }^{24}$ It is therefore reasonable to speculate that the protective effect seen with montelukast is due to its anti-inflammatory action in the small airways.

Measurement of patient-oriented assessments such as quality of life provides information on the impact of disease in patients with asthma. Both montelukast and salmeterol provided as add-on treatment to fluticasone were beneficial in improving the quality of life score, indicating improvement in the global assessment of disease control.

Lung function improved in both treatment groups. While the change in $\mathrm{FEV}_{1}$ before a bronchodilator was used was significantly better with add-on salmeterol, $\mathrm{FEV}_{1}$ after a bronchodilator had been used did not differ between the two groups, resulting in a comparatively significant loss of reversibility of $\mathrm{FEV}_{1}$ in the salmeterol-fluticasone group over the year. This observation calls for a longer prospective trial looking at the effect of long term treatment with salmeterol and montelukast on the development of lung function over time.

Role of montelukast as an anti-inflammatory agent The pathology of asthma is associated with the recruitment and influx of inflammatory cells such as eosinophils into airways and lung tissues. ${ }^{25}$ Activated eosinophils release pro-inflammatory mediators such as cytokines and cysteinyl leukotrienes. Treatment with montelukast has been shown to result in a significant reduction in the concentrations of eosinophils in the sputum and peripheral blood of asthma patients, ${ }^{26}$ implying a role for eosinophils in inflammatory processes associated with asthma. Our results show a significant difference in peripheral blood eosinophil counts between the two treatment groups and are similar to those from a previous study of patients with persistent asthma not controlled with inhaled corticosteroids. ${ }^{27}$ The observation from the induced sputum subgroup study of a significant reduction in sputum eosinophils only in the montelukast group implies that the effect seen in peripheral blood also relates to antiinflammatory changes in the lung.

The mechanism behind the protective effect of long acting $\beta$ agonists on asthma exacerbations is not clear. Some studies have proposed a link between bronchial smooth muscle tone, reactivity, and inflammation, ${ }^{28}$ and muscle cells by themselves may contribute to inflammation by mechanisms that are suppressed by salmeterol. ${ }^{29}$ It is not certain if smooth muscle relaxation by itself could serve as a protective factor against asthma exacerbations. Although our data do not address such mechanistic processes, our results show that montelukast provides protection against asthma exacerbations equivalent to that provided by salmeterol. Combining an antiinflammatory agent such as montelukast, which also exhibits bronchodilator effects, with another antiinflammatory agent such as an inhaled corticosteroid to control asthma exacerbations may constitute a logical therapeutic option in the management of chronic asthma. The absence of tolerance with montelukast in long term treatment may also be an advantage. ${ }^{12} 30$

Safety and tolerability-Both montelukast added to fluticasone and salmeterol added to fluticasone were generally well tolerated, with slightly more drug related and serious events in the salmeterol-fluticasone group compared with the montelukast-fluticasone group.

\section{Conclusion}

Current guidelines for the treatment of patients with moderate to persistent asthma recommend the use of an inhaled corticosteroid and, if needed, a long acting 


\section{What is already known on this subject}

Modern asthma guidelines advocate the use of a combination of a controller and an inhaled corticosteroid in chronic asthma treatment

Preventing asthma exacerbation is one of the most important goals in asthma management and represents a good indicator of the degree of overall disease control

Both the long acting $\beta$ agonist salmeterol and the leukotriene receptor antagonist montelukast are known to reduce the risk for asthma exacerbation when combined with an inhaled corticosteroid

No direct comparisons have been made between these drugs in a long term study where asthma exacerbation was the primary end point.

\section{What this study adds}

Adding montelukast to the treatment of patients whose symptoms remain uncontrolled with inhaled fluticasone could provide equivalent clinical control compared with adding salmeterol.

Leukotriene receptor antagonists may be an additional therapeutic option for these patients

inhaled $\beta$ agonist. The results of this study imply that the addition of montelukast in patients whose symptoms remain uncontrolled with inhaled fluticasone could be as effective as adding salmeterol in protecting against asthma exacerbations. They therefore imply that the use of leukotriene receptor antagonists such as montelukast is an additional therapeutic option for these patients.

We thank Pam S Dellea, the study monitor, and Barbara Knorr, Theodore Reiss, Jonathan Edelman, and Nancy Santanello for input into the study design and for discussions.

Contributors: JAL, LB, HB, JB, LMF, APG, TH, STH, CP, and JM designed the study; JAL, LB, HB, JB, LMF, APG, TH, STH, CP, and P S Dellea conducted the study. JM performed statistical analysis. JM, JAL, and PGP analysed the results. SBD, LB, JAL, and PGP assembled and summarised the results and wrote the paper. PGP is the guarantor.

Funding: Merck and Company Incorporated.

Competing interests: $\mathrm{LB}$ has received a fee for speaking at symposiums arranged by Merck and has received consulting fees. $\mathrm{HB}$ has received a fee from Merck for speaking, organising education, and consulting, and has received funds for research. JB has been reimbursed by Merck for attending a symposium and has received fees for both speaking and consulting. LMF has been reimbursed by Merck for attending symposiums and has received fees for both speaking and consulting. APG has received a fee from Merck for speaking and consulting and has received funds for research. TH has been reimbursed by Merck for attending a symposium and has received fees for speaking and funds for research. STH has received fees from Merck for consulting. $\mathrm{CP}$ has been reimbursed by Merck for attending a symposium and has received fees for speaking. JM, SBD, JAL, and PGP are employees of Merck and have stock options or own shares in the company.

Ethical approval: Local ethical review committees approved the study, and patients gave written informed consent.

1 National Institutes of Health, National Heart, Lung and Blood Institute. Asthma management and prevention. Global initiative for asthma. A practical guide for public health officials and health care professionals. Based on the global strategy for asthma management and prevention NHLBI/WHO workshop report. Bethesda, MD: NIH, 1995. (NIH publication No. 96-3659A) Updated report 2002. www.ginasthma.com (accessed 28 Aug 2003).

2 British asthma guidelines coordinating committee. British guidelines on asthma management: 1995 review and position statement. Thorax 1997;52:S1-24.

3 El-Radhi AS, Hogg CL, Bungre JK, Bush A, Corrigan CJ. Effect of oral glucocorticoid treatment on serum inflammatory markers in acute asthma. Arch Dis Child 2000;83:158-62.

4 Barnes PJ. Efficacy of inhaled corticosteroids in asthma. J Allergy Clin Immunol 1998:102:531-8.

5 Greening A, Wind P, Northfield M, Shaw G. Added salmeterol versus higher-dose corticosteroid in asthma patients with symptoms on existing inhaled corticosteroids. Lancet 1994;344:219-24.

6 Woolcock A, Lundback B, Ringdal N, Jacques L. Comparison of addition of salmeterol to inhaled steroids with doubling of the dose of inhaled steroids. Am J Respir Care Med 1996;153:1481-8.

7 Pauwels RA, Löfdahl C-G, Postma DS, Tattersfield AE, O’Byrne P, Barnes PJ, et al. Effect of inhaled formeterol and budesonide on exacerbations of asthma. N Engl J Med 1997;337:1405-11.

8 Laviolette M, Malmstrom K, Lu S, Chervinsky P, Pujet JC, Peszek I, et al. Montelukast added to inhaled beclomethasone in treatment of asthma Montelukast/Beclomethasone Additivity Group. Am J Respir Crit Care Med 1999;160:1862-8.

9 Drazen JM, Israel E, O'Byrne PM. Treatment of asthma with drugs modifying the leukotriene pathway. N Engl J Med 1999;340:197-206.

10 Pizzichini E, Leff JA, Reiss TF, Hendele L, Boulet LP, Wei LX, et al. Montelukast reduces airway eosinophilic inflammation in asthma: a randomized, controlled trial. Eur Respir J 1999;14:12-8.

11 Reiss TF, Sorkness CA, Stricker W, Botto A, Busse WW, Kundu S, Zhang J Effects of montelukast (MK-0476); a potent cysteinyl leukotriene receptor antagonist, on bronchodilation in asthmatic subjects treated with and without inhaled corticosteroids. Thorax 1997;52:45-8.

12 Villaran C, O'Neill SJ, Helbling A, van Noord JA, Lee TH, Chuchalin AG, et al. Montelukast versus salmeterol in patients with asthma and exerciseinduced bronchoconstriction. Montelukast/Salmeterol Exercise Study Group. J Allergy Clin Immunol 1999;104:547-53.

13 Barnes PJ. Clinical outcome of adding long-acting beta-agonists to inhaled corticosteroids. Respir Med 2001;95(suppl):S12-6.

14 Jarvis B, Markham A. Montelukast: a review of its therapeutic potential in persistent asthma. Drugs 2000;59:891-928.

15 Juniper, EF, Guyatt, GH, Willan, A, Griffith LE. Determining a minimal important change in a disease specific quality of life questionnaire. J Clin Epidemiol 1994:47:81-7.

16 Metso T, Rytilä P, Peterson C, Haahtela T. Granulocyte markers in induced sputum in patients with respiratory disorders and healthy persons obtained by two sputum-processing methods. Respir Med 2001;95:48-55.

17 International conference on harmonisation of technical requirements for registration of pharmaceuticals for human use. ICH e9. Expert Working Group. Statistical principles for clinical trials. Stat Med 1999;18:1905-42.

18 Busse, W. W. Inflammation in asthma: the cornerstone of the disease and target of therapy. J Allergy Clin Immunol 1998;102:S17-S22.

19 Shrewsbury S, Pyke S, Britton M. Meta-analysis of increased dose of inhaled steroid or addition of salmeterol in symptomatic asthma (MIASMA). BMJ 2000;320:1368-73.

20 Dworski R, Fitzgerald GA, Oates JA, Sheller JR. Effect of oral prednisone on airway inflammatory mediators in atopic asthma. Am J Respir Crit Care Med 1994;149:953-9.

21 O'Shaughnessy KM, Wellings R, Gillies B, Fuller RW. Differential effects of fluticasone propionate on allergen-evoked bronchoconstriction and increased urinary leukotriene E4 excretion. Am Rev Respir Dis increased urinas; $147: 1472-6$

22 Fish JE, Israel E, Murray JJ, Emmett A, Boone R, Yancey SW, Rickard KA Salmeterol powder provides significantly better benefit than montelukast in asthmatic patients receiving concomitant inhaled corticosteroid therapy. Chest 2001;120:423-30.

23 Nelson HS, Busse WW, Kerwin E, Church N, Emmett A, Rickard K, Knobil K. Fluticasone propionate/salmeterol combination provides more effective asthma control than low-dose inhaled corticosteroid plus montelukast. J Allergy Clin Immunol 2000;106:1088-95.

24 Kraft M, Pak J, Martin RJ, Kaminsky D, Irvin CG. Distal lung dysfunction at night in nocturnal asthma. Am J Respir Crit Care Med 2001;163:1551-6.

25 Bousquet J, Chanez P, Vignola AM, Lacoste JY, Michel FB. Eosinophil inflammation in asthma. Am J Respir Crit Care Med 1994;150:S33-38.

26 Minoguchi K, Kohno Y, Minoguchi H, Kihara N, Sano Y, Yasuhara H, Adachi M. Reduction of eosinophilic inflammation in the airways of patients with asthma using montelukast. Chest 2002;121:732-8.

27 Wilson AM, Dempsey OJ, Sims EJ, Lipworth BJ. Evaluation of salmeterol or montelukast as second-line therapy for asthma not controlled with inhaled corticosteroids. Chest 2001b;119:1021-6.

28 Crimi E, Milanese M, Pingfang S, Brusasco V. Allergic inflammation and airway smooth muscle function. Sci Total Envirom 2001:270:57-61.

29 Pang L, Knox AJ. Regulation of TNF-alpha-induced eotaxin release from cultured human airway smooth muscle cells by beta2-agonists and corticosteroids. FASEB J 2001;15:261-9.

30 Bisgaard H. Long-acting beta(2)-agonists in management of childhood asthma: A critical review of the literature. Pediatr Pulmonol 2000;29. 221-34.

(Accepted 18 July 2003) 